\title{
Correction to: Risk and Regulation in Euro Area Banks
}

\section{Correction to:}

F. Arnaboldi, Risk and Regulation in Euro Area Banks, Palgrave Macmillan Studies in Banking and Financial Institutions, https://doi.org/10.1007/978-3-030-23429-4

Author previously did not acknowledge a source of financing. This has now been acknowledged in the book.

The updated version of the book can be found at https://doi.org/10.1007/978-3-030-23429-4

(C) The Author(s) 2020

F. Arnaboldi, Risk and Regulation in Euro Area Banks, Palgrave Macmillan Studies in Banking and Financial Institutions, https://doi.org/10.1007/978-3-030-23429-4_8 